\title{
PAISAJE AGRARIO Y SOCIEDAD RURAL EN HOLGUERA (SIGLOS XIII-XVI)
}

\author{
Julián Clemente Ramos
}

Universidad de Extremadura

RESUMEN: La ocupación cristiana del término de Holguera comienza a principios del siglo XIII. En la primera mitad del XV, el terrazgo agrario ha alcanzado los límites actuales. Aparece una importante propiedad no vecinal. A finales del XV, se desarrollan las hojas de cultivo, integrando la propiedad vecinal, que desaparece, y la no vecinal, que se obtiene mediante censos enfitéuticos. El resultado es la práctica desaparición de la propiedad privada dentro del terrazgo cerealista y el desarrollo de repartos anuales vinculados a los bueyes poseídos.

PALABRAS ClAVE: Economía rural. Sociedad rural. Paisaje agrario. Hojas de cultivo. Comunalismo agrario. Baja Edad Media. Siglo XVI. Extremadura.

\section{AGRARIAN LANDSCAPE AND RURAL SOCIETY IN HOLGUERA (13TH -16TH CENTURIES)}

ABSTRACT: The beginning of the Christian occupation of the municipal district of Holguera dates to the early thirteenth century. By the mid-fifteenth century, its agricultural lands had expanded to their current limits, and come to incorporate a significant proportion of non-local property. Towards the end of the fifteenth century, Holguera's farmlands were organized into lots that absorbed both locally-beld property and non-local property, the latter being acquired by means of emphyteutic censuses. This resulted in the effective disappearance of private property within Holguera's cereal fields, which were cultivated as allotments whose annual bestowal was linked to the possession of oxen.

KEY WORDS: Rural Economy. Rural Society. Agrarian Landscape. Fields. Agrarian collectivism. Later Middle Ages. Sixteenth Century. Extremadura.

Julián Clemente Ramos es profesor en la Universidad de Extremadura. Dirección para correspondencia: Departamento de Historia, Facultad de Filosofía y Letras, Av. Universidad, s/n, 10071 Cáceres.E-mail:clemente@unex.es 


\section{INTRODUCCIÓN}

El estudio de diversos aspectos de la Baja Edad Media extremeña nos puso ante una realidad paradójica y muy difundida que, sin embargo, había pasado desapercibida: la existencia de terrazgos repartidos anualmente (Galisteo, Valencia de Alcántara, Plasencia, etc.). No se trataba de comunales rozados tempranamente sobre los que las villas y/o aldeas habían impedido su apropiación. Estábamos ante el terrazgo permanente que había sido objeto de apropiación individual desde la ocupación cristiana. Estos terrazgos comunalizados se documentaban sobre espacios organizados en hojas y con rotación colectiva. Parecía razonable relacionar ambos aspectos, aunque inicialmente ante la falta de pruebas sólo de modo hipotético ${ }^{1}$. Algunos pleitos mantenidos por la aldea de Holguera (tierra de Galisteo) que se conservan en la Chancillería de Valladolid nos han permitido analizar el proceso conjunto de gestación de las hojas de cultivo y reorganización agraria. De este modo, la génesis de estos terrazgos queda aclarada y contextualizada adecuadamente.

El estudio a escala local parecía adecuado. Se podía cartografiar con cierta precisión el terrazgo agrario y precisar sin duda alguna la comunalización de una propiedad anteriormente privada. La conformación de las hojas de cultivo y la reorganización agraria nos ha obligado a estudiar de forma conjunta el paisaje agrario y la estructura de la propiedad, en particular la mejor documentada, la no vecinal. En las páginas que siguen veremos como desde la ocupación cristiana se va gestando un modelo de ordenación del paisaje agrario que sufrirá cambios con la organización de las hojas cerealistas, que engloban la mayor parte del terrazgo cultivado.

\section{OCUPACIÓN Y EXPLOTACIÓN DEL ESPACIO (1220-C. 1450)}

Holguera aparece inmediatamente después de Las Navas de Tolosa (1212) y la conquista de Alcántara (1213) que permiten la aparición, tras el alejamiento del peligro musulmán, de un poblamiento aldeano en la Extremadura cristiana al sur de la línea Coria-Galisteo-Plasencia ${ }^{2}$. Entre principios del siglo XIII

1 Clemente Ramos, Julián, «La organización del terrazgo agropecuario en Extremadura (siglos XV-XVI)», En la España Medieval, 28 (2005), pág. 62. Realidades similares se han conservado hasta fechas muy recientes: CosTA, Joaquín, Colectivismo agrario en España, 2 vols., Zaragoza, 1983, II, págs. 99-106 y 114; ARguedas, José Ma $\mathrm{M}^{\mathrm{a}}$, Las comunidades de España y del Perú, Madrid, 1987, especialmente págs. 53-61; MARTín GALINDO, José Luis, «El colectivismo agrario de Llanaves», en: Poblamiento y actividad agraria tradicional en León, Valladolid, 1987, págs. 122-4; SÁNCHEZ GóMEZ, Luis Ángel, Sayago, ganadería y comunalismo agrario, Zamora, 1991, págs. 41-60.

2 Clemente Ramos, Julián y DE la Montaña Conchiña, Juan Luis, «La Extremadura cristiana (1142-1230). Ocupación del espacio y transformaciones socioeconómicas», Historia. Instituciones. Documentos, 21 (1994), págs. 109-110. 
y mediados del XV se desarrolla el proceso de ocupación del espacio. Aunque la documentación no nos permite trazar sus diversas etapas, el resultado se presenta con notable claridad. Podemos destacar como rasgos relevantes el desarrollo de una especialización cerealista, la construcción de un paisaje agrario organizado y el gran peso de la propiedad no vecinal, preferentemente de oligarquías ajenas a la tierra de Galisteo.

\section{PAISAJE Y ECONOMÍA RURAL}

Holguera está situada en el valle del Alagón. Presenta un paisaje alomado y suelos profundos en gran parte del término. Estos condicionantes físicos van a incidir en una especialización cerealista que es común a las zonas más llanas del término de Galisteo, que se extienden a lo largo de la margen izquierda de dicho río ${ }^{3}$. Esta especialización parece temprana y, en todo caso, está plenamente desarrollada a principios del siglo XV. En 1220, Alfonso IX donó al monasterio asturiano de Valdediós «in termino de Galisteo, in Olguero, tres iugarias de hereditate ${ }^{4}$. Posiblemente estemos ante tierras de cereal. A mediados del siglo XV, vecinos de Tornavacas se desplazan a Holguera y a otras localidades cercanas para comprar pan 5 .

Frente a la importancia del cereal, la vid parece un cultivo de importancia limitada ${ }^{6}$. Los propietarios no vecinales centran su interés de forma casi exclusiva en las tierras de cereal. Las viñas están casi ausentes. No estamos ante explotaciones especializadas sino ante propiedades que con algunas matizaciones parecen adaptarse al perfil de la estructura agraria local ${ }^{7}$ :

3 Clemente Ramos, Julián, Ordenanzas de Galisteo (1531), Cáceres, 2000, pág. 30. Esta especialización económica no puede entenderse fuera de la complementariedad que presentan el llano y la montaña, cf. CLEMENTE RAMOS, Julián, «La economía de montaña en Extremadura (siglos XV-XVI)», en: Guadalupe y la Orden Jéronima. Una empresa innovadora. Actas del Congreso, Mérida, 2008, págs. 17-30.

4 GonZález, Julio, Alfonso IX, vol. II, Madrid, 1944, doc. 394, pág. 504.

5 Archivo Histórico Nacional (=AHN), Nobleza, Frías, leg. 1367, nº 1, fol. 287 r.

6 Dentro de la tierra de Galisteo este cultivo, del que derivan importantes implicaciones sociales, sólo adquiere relevancia en Pozuelo de Zarzón: cf. Clemente Ramos, Julián, Ordenanzas de Galisteo..., pág. 31; Clemente Ramos, Julián, «Propiedad, producción y paisaje agrarios en Pozuelo a finales de la Edad Media», Anuario de Estudios Medievales, 34/1 (2004), pág. 261.

7 Hemos computado las hazas como tierras, puesto que ambos términos se utilizan a veces con un sentido indistinto: A. Ch. Valladolid, Pleitos Civiles, Zarandona y Walls (Olv), caja 1851-1, $\mathrm{n}^{\circ}$ 2, fols. 141r-149r, 150r-156r y 181v-188r; A. Ch. Valladolid, Pleitos Civiles, Lapuerta (F), caja $1155, n^{\circ} 1$, fols. 262v-270v; AHN, Nobleza, Fernán Núñez, caja 446/2, nº 39. 
CUADRO 1. PROPIEDAD NO VECINAL

\begin{tabular}{|c|c|c|c|c|c|}
\hline Propietario & Tierras & Viñas & Huertos & Casas & Otros \\
\hline Juan Sánchez (a. 1425) & 28 & - & - & 1 & \\
\hline Her. Acelgar (1430) & 16 & - & - & - & 1 palacio-casa \\
\hline Catalina Suárez (1479) & 6 & - & 2 & 1 & \\
\hline $\begin{array}{l}\text { Gómez de Trejo e Isabel } \\
\text { Bermúdez (1487) }\end{array}$ & 12 & - & - & - & \\
\hline $\begin{array}{l}\text { Juan Maldonado, regidor } \\
\text { de Coria (1521) }\end{array}$ & indet. & 1 & 1 & 1 & \\
\hline $\begin{array}{l}\text { Francisco de Trejo, regidor } \\
\text { de Plasencia (1526) }\end{array}$ & 15 & - & - & - & 1 alcácer \\
\hline Total & 77 & 1 & 3 & 3 & $\begin{array}{l}1 \text { palacio-casa } \\
1 \text { alcácer }\end{array}$ \\
\hline
\end{tabular}

La importancia del cereal es evidente. Aparecen también viñas, huertos y prados. Probablemente la propiedad sobre estos espacios estaría detentada de modo preferente por los vecinos, respondiendo al principio autárquico de toda economía precapitalista.

El terrazgo agrario se presenta en el siglo XV y principios del XVI, antes de la constitución de las hojas de cultivo, con unos rasgos nítidos. Pueden señalarse dos rasgos precisos que se ajustan a la evolución económica de la corona de Castilla: una densa ocupación y la creación de un terrazgo agrario organizado. El nivel de ocupación, que habría que vincular al menos parcialmente a un crecimiento demográfico generalizado desde las primeras décadas del siglo XV, ha producido una intensa agrarización del espacio y una casi total desaparición de la vegetación natural. El terrazgo agrario local se ajusta en sus líneas generales al modelo dominante en la meseta castellana entre los siglos XII y XV, caracterizado por la separación de los distintos cultivos y la creación de pagos de viñas y huertos ${ }^{8}$.

$\mathrm{Al}$ menos desde principios del siglo XV, Holguera presenta un paisaje intensamente ocupado. Las tierras de cultivo, incluyendo la dehesa boyal, han

8 BARrios García, Ángel, Estructuras agrarias y de poder en Castilla: el ejemplo de Ávila (10851320), vol. II, Salamanca, 1984, págs. 90-97; ALFONSO ANTÓN, Isabel, La colonización cisterciense en la meseta del Duero. El ejemplo de Moreruela (siglos XII-XIV), Zamora, 1983, págs. 152-3; MARTíneZ SOPENA, Pascual, La Tierra de Campos occidental. Poblamiento, poder y comunidad del siglo X al XIII, Valladolid, 1985, págs. 545-6; VILlar GARCíA, Luis Miguel, La Extremadura castellano-leonesa. Guerreros, clérigos y campesinos (711-1252), Valladolid, 1986, págs. 357 y 370; RoDRíGUEZ-PICAVEA, Enrique, La formación del feudalismo en la meseta meridional castellana. Los señoríos de la Orden de Calatrava en los siglos XII-XIII, Madrid, 1994, págs. 207-9; CLEMENTE RAMOS, Julián, «La organización del terrazgo...», págs. 4980; PASTOR De TOGNERI, Reyna, «Poblamiento, frontera y estructura agraria en Castilla la Nueva (1085-1230)», Cuadernos de Historia de España, XLVII-XLVIII (1968), págs. 199-211. 
alcanzado los límites del espacio agrario actual. El bosque ha desaparecido de forma prácticamente total por debajo de los trescientos metros de altitud. En el sureste del término, en la dehesa boyal, como seguramente en las zonas más elevadas o en la dehesa de Villasirga, aprovechada hacia 1500 de forma conjunta por el conde de Osorno y Riolobos, se desarrolla un paisaje adehesado. A finales del siglo XVI, nos constan las penas que diversos vecinos de esta localidad sufren en la dehesa boyal de Holguera. El estrato arbóreo se compone exclusivamente de encinas ${ }^{9}$. Este receso del bosque no afecta al abastecimiento de madera. Si bien, puede hablarse de términos aldeanos, éstos no ocupan toda la jurisdicción y no pueden confundirse con los actuales. Para el aprovechamiento del bosque, la jurisdicción de Galisteo en su conjunto funciona como una unidad. Holguera y Riolobos se abastecen de madera en Cabañas Mojadas (quizás Navasmojadas, al norte del Alagón y lindando con este río) y Valtahajo ${ }^{10}$. Dentro del espacio agrario de Holguera aparece matorral de degradación, a veces formando manchas espesas de reducida extensión. La especie dominante es la escoba. Junto a la Peña Lagartera, en el camino de Grimaldo, aparece «un escobal espeso", quizás el mismo cerro Escoboso que se cita junto a la misma ${ }^{11}$. En un apeo de 1508, en una tierra que partía del Helechar, se cortaron «unas ramas de escobas». Se cita un escobar en el camino de Coria ${ }^{12}$. Al sur del término, aparecen junto al arroyo de los pradillos «tomillares» que ocupan espacios comunales ${ }^{13}$. El topónimo «helechar», que aparece en una posición muy meridional, parece denotar la proliferación de un matorral más húmedo en cotas más elevadas.

La vegetación de ribera también ha sufrido un fuerte receso. Algunos topónimos como los arroyos de los Pradillos o del Nogal denotan el aprovechamiento humano de estos espacios y su conversión en huertas o prados. La vegetación debía ser escasa y degradada. Aparece un «Valdeyuncales» y una «Tamuja» en un arroyo que atraviesa el camino de Holguera a Torre de Vigo, situada cerca de la Vía de la Plata o Guinea ${ }^{14}$.

Dos tercios del actual término de Holguera son espacios sin vegetación arbórea natural. Quercíneas y árboles de ribera han sido eliminados. El fuego ha debido ser un instrumento central, como denota el topónimo cenicero, y necesario, puesto que estaríamos ante espacios posiblemente desocupados durante mucho tiempo que debían contar con una densa vegetación ${ }^{15}$.

9 A. Ch. Valladolid, Pleitos Civiles, Zarandona y Walls (Olv), caja 1851-1, no 2, fols. 13 r y $14 \mathrm{r}$.

10 A. G. Simancas, Consejo Real, Leg. 9, expág. 7-2, fol. 27r.

11 A. Ch. Valladolid, Pleitos Civiles, Lapuerta (F), caja 1155 , n ${ }^{\circ} 1$, fols. $265 \mathrm{v}$ y $269 \mathrm{v}$.

12 A. Ch. Valladolid, Pleitos Civiles, Lapuerta (F), caja 1155, no 1, fol. 88r; A. Ch. Valladolid, Pleitos Civiles, Zarandona y Walls (Olv), caja 1851-1, $\mathrm{n}^{\circ}$ 2, fol. $154 \mathrm{v}$.

13 AHN, Nobleza, Fernán Núñez, caja 446/2, n 33, fol. 1r.

14 A. Ch. Valladolid, Pleitos Civiles, Zarandona y Walls (Olv), caja 1851-1, no 2, fol. 142v; AHN, Nobleza, Fernán Núñez, caja 446/2, nº 33, fol. 1r.

15 Clemente Ramos, J. y De la Montaña Conchiña, J.L., «La Extremadura cristiana...», pág. 93. 
La ocupación del espacio se ha realizado de forma selectiva. Por encima de la curva de nivel 300 se desarrolla una dedicación pecuaria casi exclusiva. Próxima a la aldea y junto a la curva de nivel citada se sitúa la dehesa boyal, que en su origen incluyó la de la Barranca ${ }^{16}$. En la zona meridional del término aparece la de Villasirga (actual Villasilvo).

Junto a la aldea, se ha extendido el ejido, denominado indistintamente como «exido de Olguera», «ejido del rodeo» o «exido de los ansares» ${ }^{17}$. No podemos determinar su extensión. En los límites del mismo comienza el terrazgo cerealista. Se alude en ocasiones a tierras que salen del ejido ${ }^{18}$. El ejido, pese a su carácter inicialmente comunal, ha sido ocupado parcialmente por diversos cultivos que encuentran acomodo preferente cerca de la población, como huertos o viñas. El cultivo hortícola se concentra fundamentalmente junto a los arroyos de Cenicero y Ribera, las dos mayores corrientes de agua del término. También se documenta junto al arroyo de Doña Pascuala, aunque no sabemos si podemos hablar de un auténtico pago ${ }^{19}$. El arroyo de Cenicero posiblemente estaría jalonado de huertos en gran parte de su curso. Aparece «una tierra que se nonbra de los hortezuelos» que se extiende entre el límite con Riolobos y la dehesa boyal, y llega a atravesar el arroyo. En su confluencia con la Ribera aparecen huertos y viñas $^{20}$. Junto a este arroyo también aparece una tierra «que sale del arroyo de Olguera cave los guertos» ${ }^{21}$. Las viñas se sitúan cerca de la población, hacia el oeste. Se trata de un espacio en el que permanecen huellas toponímicas como el Viñaco, repetidamente citado en la documentación, o las viñas de Abajo o Arriba. Las referencias a «las viñas» o «las paredes de las viñas» no dejan lugar a dudas sobre la existencia de un pago vitícola en esta zona ${ }^{22}$.

Frente a la concentración de huertos y viñas, los prados se caracterizan por su dispersión por todo el terrazgo aprovechando la disponibilidad de agua o la humedad edáfica. No se documentan junto a la Ribera o el Cenicero. Sólo en un caso se produce una cierta concentración o pequeño pago. Al sur del término, cerca del límite con la tierra de Garrovillas (Cañaveral), aparece un «camino que va a los pradillos e el arroyo de los pradillos» ${ }^{23}$. En los demás casos, ca-

16 Archivo de la Catedral de Coria, leg. 769, libro de deslindes, ff. 31r-31v, a. 1707 (disponemos de está información por cortesía de D. ${ }^{\text {a }}$ Fátima Cotano Olivera).

17 A. Ch. Valladolid, Pleitos Civiles, Lapuerta (Olv), caja 1226, $\mathrm{n}^{\circ}$ 6, fol. 2r; A. Ch. Valladolid, Pleitos Civiles, Zarandona y Walls (Olv), caja 1851-1, $\mathrm{n}^{\circ}$ 2, fol. 85v.

18 «E mas otra tierra que sale del exido de Olguera e descaveça en tierras de Juan Fernandez de Medina» (A. Ch. Valladolid, Pleitos Civiles, Zarandona y Walls (Olv), caja 1851-1, n ${ }^{\circ}$ 2, fol. 152r).

19 A. Ch. Valladolid, Pleitos Civiles, Zarandona y Walls (Olv), caja 1851-1, no 2, fol. 257r; A. Ch. Valladolid, Pleitos Civiles, Lapuerta (Olv), caja 1226, $\mathrm{n}^{\circ}$ 6, fols. 1r-2v.

20 A. Ch. Valladolid, Pleitos Civiles, Zarandona y Walls (Olv), caja 1851-1, no 2, fol. 150r; A. Ch. Valladolid, Pleitos Civiles, Lapuerta (F), caja 1155, $\mathrm{n}^{\circ}$ 1, fol. $270 \mathrm{r}$.

21 A. Ch. Valladolid, Pleitos Civiles, Zarandona y Walls (Olv), caja 1851-1, no 2. fol. 155v.

22 A. Ch. Valladolid, Pleitos Civiles, Zarandona y Walls (Olv), caja 1851-1, no 2, fol. 143v; A. Ch. Valladolid, Pleitos Civiles, Lapuerta (F), caja 1155, $\mathrm{n}^{\circ}$ 1, fol. 269r (Valdefreiles).

23 AHN, Nobleza, Fernán Núñez, caja 446/2, nº 39, fol. 1 r. 
da prado ha cogido un nombre derivado normalmente de su ubicación: Valdelavaca, Valdefuentes, Hornillo, Fuente Vieja, Fuente de Malpartida, Carril o Redondo ${ }^{24}$. Esta proliferación de prados por todo el término mediante el aprovechamiento de cualquier ubicación adecuada (arroyo, fuente) quizás se deba a una dedicación ganadera de cierta importancia.

Estos espacios no cerealistas se caracterizan por su posible cercamiento y su limitada extensión. Los huertos estarían habitualmente cercados, aunque el hecho de que se aluda a «un guerto zercado» parece indicar que no todos lo estarían a principios del siglo XVI ${ }^{25}$. Igualmente, se alude a las paredes de las viñas. Nada se dice sobre los prados, aunque su ubicación junto al terrazgo cerealista haría aconsejable que dispusieran de alguna barrera protectora. La necesidad de precisar la existencia de «un guerto de piçarra» parece indicar el predominio de las cercas realizadas de madera, muy frecuentes en la jurisdicción de Galisteo a finales de la Edad Media ${ }^{26}$. Sobre la extensión de estos cultivos no tenemos ninguna información precisa. La alusión, sin embargo, a «hortezuelos» o "pradillos» denota que en bastantes casos estaríamos ante extensiones modestas.

El terrazgo cerealista es omnipresente por debajo de los trescientos metros de altitud. Podemos decir que la ocupación es prácticamente total. En numerosas ocasiones se alude a tierras con una ubicación periférica. En la escritura de deslinde presentada por Juan Sánchez en 1425, tres tierras limitan con el término de Riolobos y cinco con el de Coria. A finales del siglo XIV y comienzos del XV se ha desarrollado un paisaje completamente agrarizado en los dos tercios del término que presentan buenas condiciones para el cultivo. Todo esto nos hace pensar que el espacio susceptible de una futura ocupación mediante rozas es muy limitado y ofrece condiciones poco adecuadas. En Holguera, hacia 1400, la ocupación del término puede darse por finalizada.

Disponemos de algunos datos para estudiar el parcelario cerealista. Conocemos la extensión de catorce parcelas que conformaban la herencia del comendador Hernando de Trejo y de diez de las once que acensó el bachiller Juan de Villalobos (parte de la herencia de Juan Sánchez) a Holguera ${ }^{27}$. También sabemos la extensión media de las parcelas de Gómez de Trejo e Isabel Bermúdez ${ }^{28}$. Aunque son documentos tardíos, podemos retrotraer su información con seguridad a la primera mitad del siglo XV e incluso a finales del XIV.

24 A. Ch. Valladolid, Pleitos Civiles, Zarandona y Walls (Olv), caja 1851-1, $\mathrm{n}^{\mathrm{o}}$ 2, fols. 254v264r; A. Ch. Valladolid, Pleitos Civiles, Zarandona y Walls (Olv), caja 1851-1, n ${ }^{2}$, fols. 150r-156r.

25 A. Ch. Valladolid, Pleitos Civiles, Zarandona y Walls (Olv), caja 1851-1, $\mathrm{n}^{\circ} 2$, fol. 181v.

26 A. Ch. Valladolid, Pleitos Civiles, Zarandona y Walls (Olv), caja 1851-1, $\mathrm{n}^{\circ}$ 2, fol. $257 \mathrm{r}$. Sobre los materiales usados en los cercados agrarios, CLEMENTE RAMOS, Julián, «Desarrollo agrario y explotación forestal en la tierra de Galisteo a finales de la Edad Media», en: Actas de las II Jornadas de Historia Medieval de Extremadura, Mérida, 2005, pág. 64.

27 A. Ch. Valladolid, Pleitos Civiles, Lapuerta (Olv), caja 1226, $\mathrm{n}^{\circ}$ 6, fols. 1r-3v; AHN, Nobleza, Fernán Núñez, caja 446/2, nº 33 y 39.

28 A. Ch. Valladolid, Pleitos Civiles, Zarandona y Walls (Olv), caja 1851-1, nº 2, 141r-149r. 
Se trata de importantes propietarios no vecinales que poseían en conjunto más de seiscientas fanegas. Los datos que siguen, por tanto, sólo definen el tipo de parcelas que integran la media y gran propiedad extravecinal. La extensión media de las parcelas poseídas por Hernando de Trejo, el bachiller Juan de Villalobos y Gómez de Trejo es de 18,26 fanegas (12,07; 13,85 y 29,17 fanegas respectivamente). Se trata, sin duda, de parcelas grandes sobre todo si se considera que un campesino local que dispusiese de una pareja de bueyes podría disponer en el mejor de los casos de diez-quince fanegas ${ }^{29}$. La propiedad vecinal forzosamente estaría compuesta por parcelas más pequeñas ${ }^{30}$.

Las parcelas del comendador Hernando de Trejo y el bachiller Juan de Villalobos tenían las siguientes extensiones:

\section{CUADRO 2. PARCELARIO CEREALISTA (PROPIEDAD NO VECINAL)}

\begin{tabular}{|c|c|c|c|}
\hline Fanegas de sembradura & Tierras & Total fanegas & $\begin{array}{c}\text { Fanegas } \\
(\%)\end{array}$ \\
\hline 1 & 1 & 1 & 0,32 \\
\hline 2 & 5 & 10 & 3,25 \\
\hline 3 & 2 & 6 & 1,95 \\
\hline 4 & 2 & 8 & 2,60 \\
\hline 5 & 3 & 15 & 4,88 \\
\hline 6 & 1 & 6 & 1,95 \\
\hline
\end{tabular}

29 El comendador Hernando de Trejo, cuya herencia ascendía a 169 fanegas de tierra en Holguera tenía derecho a llevar «quinze bueyes en la dehesa boyal de Holguera» (AHN, Nobleza, Fernán Núñez, caja 446/2, no 39, fols. 2v-3r); Galisteo establece en las ordenanzas de 1531 que para que una yunta de bueyes disfrute de la dehesa boyal debe labrar ocho fanegas de barbecho en la vertiente izquierda del Alagón y cinco en la derecha (CLemente Ramos, Julián, Ordenanzas de Galisteo..., pág. 30).

30 Durante los siglos XIII-XIV, en los terrazgos agrarios de la meseta dominan, en general, las parcelas pequeñas y su extensión media normalmente se sitúa por debajo de las cinco fanegasobradas (REgLero De LA Fuente, Carlos Manuel, Espacio y poder en la Castilla medieval. Los Montes de Torozos (siglos X-XIV), Valladolid, 1994, págs. 199 y 201; BARRIOS GARCíA, Estructuras agrarias y de poder..., pág. 106; PÉREZ MOREDA, Vicente, «El dominio territorial del cabildo», en: Propiedades del cabildo segoviano, sistemas de cultivo y modos de explotación de la tierra a fines del siglo XIII, Salamanca, 1981, pág. 59). En la baja Edad Media y principios del siglo XVI, la extensión de las parcelas disminuye sensiblemente, pudiendo hablarse en alguna ocasión de «un complejo rompecabezas compuesto por una gran multitud de minúsculas piezas» (VACA LORENZO, Ángel, «La configuración de un paisaje agrario orgánico en la baja Edad Media. El cuadrante nororiental de la provincia de Zamora», Estudios Geográficos, LIII/209 (1992), pág. 723; igualmente, OlIVA HerRER, Rafael Hipólito, La Tierra de Campos a fines de la Edad Media. Economía, sociedad y acción política campesina, Valladolid, 2002, pág. 119; AsEnJo GonZÁlez, María, Segovia. La ciudad y su tierra a fines del medievo, Segovia, 1986, pág. 149; SánCHez BenITO, José María, Las tierras de Cuenca y Huete en el siglo XIV. Historia económica, Cuenca, 1994, págs. 123-4). 


\begin{tabular}{|c|c|c|c|}
\hline Fanegas de sembradura & Tierras & Total fanegas & $\begin{array}{c}\text { Fanegas } \\
(\%)\end{array}$ \\
\hline 7,5 & 1 & 7,5 & 2,44 \\
\hline 12 & 3 & 36 & 11,71 \\
\hline 13 & 1 & 13 & 4,23 \\
\hline 15 & 1 & 15 & 4,88 \\
\hline 60 & 2 & 60 & 19,51 \\
\hline 70 & 1 & 60 & 19,51 \\
\hline Total & 1 & 70 & 22,76 \\
\hline & 24 & 307,5 & 99,99 \\
\hline
\end{tabular}

En la propiedad no vecinal predominan las parcelas que no superan las cinco fanegas $(54,17 \%)$ pero las de treinta o más acumulan una superficie muy superior $(61,78 \%$, por el $13 \%$ de las primeras). En conjunto, podemos afirmar que las pequeñas parcelas serían mucho más numerosas pero las de quince o más fanegas coparían una parte significativa de la superficie cerealista, debido a la importancia de la propiedad no vecinal.

El parcelario cerealista presenta de modo general una forma alargada:

«tierra que sale de tierra de Gutierre Gonçalez e de Fernan Rodriguez que passa el arroyo e la cañada que es zerca de la Torrezilla e descaveça en tierra del cabildo que a por linderos de la una parte tierra de Gutierre Gonçales e de la otra parte tierras del dicho cabildo» 31 .

Este es el modelo que de modo repetitivo se utiliza para deslindar las tierras. Están limitadas en su parte inferior y superior por otras tierras, espacios comunales, el término de otro concejo o algún accidente topográfico. Sólo se enumeran dos linderos laterales. Las parcelas son predominantemente rectangulares, algo habitual en paisajes agrarios maduros ${ }^{32}$. Sobre más de cien parcelas, el 65,74\% está limitado por otras dos; un 25\% adicional, en uno o en ambos lados linda con más de una parcela o está rodeada por una sola. Estos porcentajes serían superiores si consideramos que en un 4,63\% sólo se especifica un lindero, aunque es bastante probable que hubiese otro más. Algunas tierras de gran extensión presentan formas más irregulares. La tierra de los hortezuelos «entra un pedazo de ella en lo de Riolovos (...) e otro pedazo della pasa el arroyo de Cenizeros e el camino de Plassençia» ${ }^{33}$. La tierra del Tejero

31 A. Ch. Valladolid, Pleitos Civiles, Zarandona y Walls (Olv), caja 1851-1, no 2, fol. 153.

32 Gavilán, Enrique, El dominio de Párraces en el siglo XV. Un estudio sobre la sociedad feudal, Zamora, 1986, pág. 256; SÁNCHeZ Benito, José María, Las tierras de Cuenca y Huete..., págs. 1256; Clemente Ramos, Julián, «Propiedad, producción y paisaje...», pág. 270.

33 A. Ch. Valladolid, Pleitos Civiles, Zarandona y Walls (Olv), caja 1851-1, no 2, fol. 151. 
«sale de un braço de Valdematajijos (...) e haze llave en tierra de Hernan Martin el Gordo (...) torna a hazer llave en tierra de Juan Hernandes de Medina (...) e descabeça este braço en la cañada donde dizen el mojon de Toribio Martin (...) e çerca una tierra que se dize del Mal Lavado (...) pasa el arroyo de Ceniceros (...) torna a pasar a Çenizeros por el fondo del charco blanco e pasa el camino que va a Plasençia»34.

En cualquier caso, el parcelario presenta unas formas que parecen bastante regulares.

El resultado final del proceso de ocupación cristiana aparece con nitidez en la primera mitad del siglo XV. Hacia 1450, cultivos y comunales (ejido, dehesa boyal) ocupan todo el terrazgo agrario actual. Estamos ante una intensa ocupación que no posibilita ningún incremento significativo del espacio cultivado. El terrazgo agrario resultante se caracteriza por la segregación de tierras, viñas y huertos, siguiendo las pautas dominantes en la corona de Castilla entre los siglos XII al XV. Sobre esta realidad va a incidir el crecimiento de la población, la creciente escasez del bosque y la subsiguiente necesidad de optimizar el aprovechamiento de las tierras de cereal.

\section{LA PROPIEDAD AGRARIA: OLIGARQUÍA NO VECINAL Y CAMPESINADO}

Junto a la preferente dedicación cerealista, otro rasgo llamativo es la importancia de la propiedad no vecinal, algo común a las zonas sedimentarias de la tierra de Galisteo ${ }^{35}$. Aunque no podemos precisar su ritmo de desarrollo, parece claro que a lo largo del periodo estudiado y antes de la constitución de las hojas se aprecian dos fases nítidamente diferenciadas. La primera se extiende hasta comienzos del siglo XV. En ella, la oligarquía de Galisteo, en concurrencia desde el principio o sólo más tardíamente con otras oligarquías comarcanas, ha debido tener un papel importante. Numerosos vecinos de esta villa venden sus propiedades antes de 1406 a Gonzalo Bermúdez de Trejo y a su hijo Gutiérrez González de Trejo, señores de Grimaldo ${ }^{36}$. Desde entonces, este

34 AHN, Nobleza, Fernán Núñez, caja 446/2, no 39, fol. 1.

35 Dentro de la tierra de Galisteo, Pozuelo presenta a finales del siglo XV un contraste claro, con una limitada presencia de la propiedad no vecinal que se centra casi exclusivamente en el viñedo (CLEMENTE RAMOS, Julián, «Propiedad, producción y paisaje...», Cuadro 1, pág. 253). La acumulación de propiedades aldeanas por sectores urbanos es algo habitual en la baja Edad Media (BARRIOS GARCíA, Ángel, Estructuras agrarias y de poder..., pág. 176; CASAdo AlONSO, Hilario, Señores, mercaderes y campesinos. La comarca de Burgos a fines de la Edad Media, Madrid, 1987, pág. 516; Clemente RAmos, Julián, "Ciudad y territorio en la Extremadura medieval [siglo XIII-c. 1550]», en: La ciudad Medieval y su influencia territorial (Nájera. Encuentras internacionales del Medioevo 2006), págs. 100-101; SÁNCHEZ RUBIO, Ma Angeles, El concejo de Trujillo y su alfoz en el tránsito de la Edad Media a la Edad Moderna, Cáceres, 1993, págs. 448-9).

36 En una sentencia del bachiller Juan Ruiz de Medina de 1406 se alude a «las casas e eredades 
colectivo pierde todo protagonismo. Es llamativo que mientras miembros cualificados de las oligarquías de algunas villas importantes participan en la propiedad adehesada y alcanzan un importante nivel social, en Galisteo, a finales del siglo XV, sólo documentamos un modesto grupo de hidalgos ${ }^{37}$. Es posible que la oligarquía de Plasencia, sobre todo, haya tenido un protagonismo importante desde muy pronto. En todo caso, «ansy vesinos de Prasençia como de Coria e de otras partes» realizan numerosas apropiaciones entre la muerte de Sancho de Alburquerque (1374) y el control del señorío, en calidad de consorte, por Fernando de Antequera $(1393)^{38}$. Desde principios del siglo XV, la propiedad oligárquica será de modo prácticamente exclusivo no vecinal.

La importancia de la propiedad no vecinal, aunque no puede cuantificarse con precisión, está fuera de toda duda. Disponemos de datos parciales relativos al linaje Trejo y al «caballero» Juan Sánchez, vinculados al territorio placentino. El comendador Hernando de Trejo, seguramente hijo de Francisco de Trejo y nieto de Gutiérrez González de Trejo, señor de Grimaldo, poseyó antes de 1521 ciento sesenta y nueve fanegas de sembradura, sin contar una tierra de catorce fanegas situada en la vecina localidad de Riolobos ${ }^{39}$. Gómez de Trejo y su mujer Isabel Bermúdez, vecinos de la aldea placentina de Casas de Millán, venden en 1487 a las monjas de San Alfonso de Toledo doce tierras que suman trescientas cincuenta fanegas ${ }^{40}$. En 1528, el bachiller Juan de Villalobos, nieto de Juan Sánchez, acensa once tierras de las veintiocho que tuvo su abuelo, nueve de las cuales alcanzan las ciento treinta y seis fanegas y media ${ }^{41}$. Estas 655,5 fanegas sólo representan una parte difícil de precisar pero sin duda limitada de la propiedad no vecinal. Hay que considerar, junto a propietarios de cierta importancia y a otros más numerosos de menor entidad, unidades compactas como las Casas del Arroyo y el Acelgar, citada en alguna ocasión como aldea ${ }^{42}$ y

que Gonçalo Bermudez e el dicho Gutierre Gonçales de Trexo conpraron en Olguera en termino de la dicha billa de Galisteo de Julian Sanchez, fixo de Bartolome Sanches, e de Doña Benita, su mujer, e de Santiago Alonso, fixo de Julian Alonso, e de Teresa Alonso, fixa de Julian Alonso, e de Fernan Nuñez, fixo de Marina Perez, e de el dicho su fixo, e de Marina Alonso, mujer que fue Juan Alonso, e de Fernan Martinez, fixo de Juan Martinez, e de Marina Fernandez, su mujer, e de Marin Alonso, vecinos de la dicha billa de Galisteo» (A. Ch. Valladolid, Pleitos Civiles, Zarandona y Walls [Olv], caja 1852-1, $\mathrm{n}^{\mathrm{O}} 2$, fols. 41v-42r). Sobre ambos personajes, GERBET, $\mathrm{M}^{\mathrm{a}}$ Claude, La noblesse dans le royaume de Castille. Ètude sur ses structures sociales en Estrémadure de 1454 a 1516, París, 1979, anexo III, cuadro genealógico de los Trejo.

37 Clemente Ramos, Julián, La tierra de Medellín (1234-c. 1450). Dehesas, ganadería y oligarquía, Badajoz, 2007, págs. 87-121; GARCía Oliva, Mª Dolores, Organización y social del concejo de Cáceres y su tierra en la Baja Edad Media, Cáceres, 1990, págs. 143-157; SÁNCHEZ RuBIO, M ${ }^{\mathrm{a}}$ Angeles, El concejo de Trujillo y su alfoz..., págs. 244-251.

38 A. Ch. Valladolid, Pergaminos, caja $40, \mathrm{n}^{\circ} 3$.

39 AHN, Nobleza, Fernán Núñez, caja 446/2, nº 33.

40 A. Ch. Valladolid, Pleitos Civiles, Zarandona y Walls (Olv), caja 1851-1, nº 2, fols. 141r-149r.

41 A. Ch. Valladolid, Pleitos Civiles, Lapuerta (Olv), caja 1226, $\mathrm{n}^{\circ} 6$.

42 A. Ch. Valladolid, Pleitos Civiles, Zarandona y Walls (Olv), caja 1852-1, nº 2, fol. 26r. 
cuya extensión debería ser de algún centenar de fanegas ${ }^{43}$. Es sintomático que a finales del siglo XVI, 486,5 fanegas y dos tierras de extensión no precisada devenguen un censo de treinta fanegas de las 171,32 fanegas que reciben, excluido el conde, los propietarios no vecinales.

Algunos deslindes de propiedades pueden darnos una idea adicional de la importancia de la propiedad no vecinal ${ }^{44}$ :

CUADRO 3. PARCELAS Y PROPIEDAD

\begin{tabular}{|l|c|c|}
\hline Propietario & Propiedad vecinal & Propiedad no vecinal \\
\hline Juan Sánchez (c. 1425) & 43 & 21 \\
\hline División de la tierra del Acelgar (1430) & 12 & 17 \\
\hline Catalina Suárez (1479) & 3 & 26 \\
\hline Conde de Osorno (1485) & 11 & 56 \\
\hline Concejo de Holguera (1485) & 14 & 26 \\
\hline Gómez de Trejo e Isabel Bermúdez (1487) & 14 & 35 \\
\hline Francisco de Trejo (c. 1521) & 26 & 11 \\
\hline Total & 123 & 192 \\
\hline
\end{tabular}

En conjunto, podemos considerar que la propiedad no vecinal u oligárquica tiene en el siglo XV un papel predominante en Holguera. Esta propiedad parece dotada de gran estabilidad. La herencia parece el mecanismo habitual de acceso a su disfrute. En la segunda mitad del XV sólo el conde de Osorno desarrolla una importante actividad adquisitiva.

Poco podemos indicar sobre la propiedad campesina o vecinal, que representa un componente minoritario. Parece probable la existencia de un grupo que goza de una situación económica desahogada. Es llamativo que en 1541 Alonso Pérez Calvo y su mujer Isabel Hernández, vecinos de Holguera, entreguen la haza del bachiller por un censo enfitéutico de «catorçe hanegas de pan trigo e seis fanegas de zevada» ${ }^{45}$. En un interrogatorio presentado en 1503 por Duarte Enrique, representante del conde de Osorno, se indica que «a un vezino solo del dicho logar Olguera le copo çiento e veynte fanegadas de tierra en la

43 Estos datos, parciales, hay que compararlos con las 4351 fanegas de cereal cultivadas a mediados del siglo XVIII (A. G. Simancas, Catastro de Ensenada, Respuestas Generales, lib. 142, fol. 439v). MADOZ, Pascual, Diccionario histórico-geográfico de Extremadura, Cáceres, 1955, vol. III, pág. 159, solo cuantifica dos mil fanegas de tierra de labor, pero quizás estemos ante distintas medidas.

${ }_{44}$ Cf. nota 7; A. Ch. Valladolid, Pleitos Civiles, Zarandona y Walls (Olv), caja 1851-1, no 2 , fols. $254 \mathrm{v}-264 \mathrm{r}$

45 A. Ch. Valladolid, Pleitos Civiles, Zarandona y Walls (Olv), caja 1851-1, n 2, fol. $224 \mathrm{r}$. 
dicha hoja» ${ }^{46}$. Ruy González y Fernando de Sepúlveda y su mujer venden once y nueve parcelas respectivamente al conde de Osorno antes de $1485^{47}$. Algunos vecinos, por tanto, han llegado a poseer antes de la constitución de las hojas de cultivo propiedades de cierta entidad. La existencia de grupos campesinos acomodados o enriquecidos es una realidad consolidada a finales de la Edad Media y comienzos de la Moderna ${ }^{48}$.

Sin duda, estamos ante situaciones excepcionales. La mayor parte de los vecinos tendría un nivel modesto. Esta circunstancia debió facilitar la renuncia a la propiedad y su sustitución por un derecho de usufructo vinculado a la disponibilidad de bueyes. Para la mayoría esto supondría una mejora y la posibilidad de acceder a explotaciones adecuadas a sus necesidades.

\section{TERRAZGO CEREALISTA Y HOJAS DE CUlTivo (SIGlOS XV-XVI)}

Hacia 1450, quizás antes, la ocupación del espacio del actual término de Holguera está prácticamente finalizada. Entre las últimas décadas del siglo XV y mediados del XVI, asistimos a cambios que están profundamente imbricados. Los condes de Osorno, que obtienen la jurisdicción de la tierra de Galisteo en 1429, desarrollan una importante acumulación patrimonial. Sobre este espacio colmatado se van a conformar las hojas de cultivo, proceso común a toda la margen izquierda del río Alagón, zona de especial desarrollo cerealista. Asistimos, por tanto, desde mediados del siglo XV a transformaciones significativas en el modelo señorial y la organización del paisaje agrario.

46 A. G. Simancas, Consejo Real, leg. 662, nº 2, fol. 33r.

47 A. Ch. Valladolid, Pl. Civiles, Zarandona y Walls (Olv), caja 1851-1, $\mathrm{n}^{\circ}$ 2, fols. 252r-265r.

48 Lo hemos documentado en diversos estudios: "Martín Sancho (siglos XIV-XVI). Un despoblado bajomedieval en la tierra de Medellín», Hispania. Revista Española de Historia, XLVI/223 (2006), pág. 494; «La ganadería porcina de Jarandilla de la Vera a mediados del siglo XV», en: Os reinos ibéricos na Idade Média. Livro de Homenagem ao Professor Doutor Humberto Carlos Baquero Moreno, vol. II, Oporto, 2003, pág. 749; «Notas sobre la ganadería estante de Medellín (1488)», En la España Medieval, 31 (2008), págs. 153, 156 y 158-9; La tierra de Medellín (1234-c. 1450)..., págs. 122-3. El desarrollo de un sector pechero enriquecido en el siglo XV se presenta como una realidad consolidada en todo la corona de Castilla: MOLENAT, Jean-Pierre, Campagnes et Monts de Tolede du XI au XV siécle, Madrid, 1997, págs. 541-2; SuÁrez ÁlvareZ, María Jesús, La villa de Talavera y su tierra en la Edad Media (1369-1504), Oviedo, 1982, págs. 147-8; ASENJo GoNZÁLEZ, María, "Labradores ricos': nacimiento de una oligarquía rural en la Segovia del siglo XV», En la España Medieval, 4/1 (1984), pág. 64; RODRíGUEZ LLOPIS, Miguel, Señoríos y feudalismo en el reino de Murcia. Los dominios de la Orden de Santiago entre 1440 y 1515, Murcia, 1984, págs. 178-84; Goicolea Julián, Francisco Javier, Haro: una villa riojana del linaje Velasco a fines del Medievo, Logroño, 1999, pág. 45. 


\section{LA PROPIEDAD CONDAL}

La acumulación de propiedades por los condes de Osorno es un elemento a considerar desde la segunda mitad del siglo XV. Esta actuación, con profundas implicaciones sociopolíticas, presenta aspectos comunes con otros nobles titulados que reciben jurisdicciones en el segundo cuarto del siglo XV. En los antiguos dominios de Sancho de Alburquerque y sus descendientes (Leonor de Alburquerque, consorte de Fernando de Antequera, y los infantes de Aragón) este proceso supone un cambio en el modelo sociopolítico. Mientras los antiguos señores han llevado una política fundamentada en el consenso social y el establecimiento de vínculos con las oligarquías locales, los nuevos van a intentar asentar un sólido dominio solariego, optimizar la detracción de rentas y controlar estrictamente todos los resortes del poder. Se trata de una autoridad jurisdiccional mucho más próxima, sin duda para disgusto de campesinos e hidalgos. Aunque el fenómeno apenas ha sido esbozado para Galisteo, no ofrece dudas la existencia de una dinámica muy próxima a la de otros señoríos extremeños que presentan una situación similar. Por todo lo indicado, la concesión de Galisteo y su tierra a Garcí Fernández Manrique, conde de Castañeda, en 1429, marca en la jurisdicción una ruptura significativa ${ }^{49}$.

La nueva dependencia jurisdiccional va a incidir de modo preciso en Holguera. Los nuevos señores de Galisteo van a realizar una acumulación patrimonial importante. Esta acumulación tiene dos vertientes: la apropiación de dehesas y la compra de heredades agrarias. Dentro del actual término de Holguera, los condes poseen la dehesa de Villasilvo (Villasirga) al sur. Al norte, dentro de lo que hoy constituye el término de Riolobos, controlan la Dehesa Vieja y la Dehesilla. Estas y otras las aprovechan conjuntamente con esta aldea ${ }^{50}$. El terrazgo cerealista local se encuentra de este modo rodeado por propiedades condales, factor que no debemos soslayar.

49 Montero Tejada, Rosa $\mathrm{M}^{\mathrm{a}}$, «Violencia y abusos en los señoríos del linaje Manrique a fines de la Edad Media», En la España Medieval, 20 (1997), págs. 377 y 340, señala cómo «Los Manrique, como otros de su clase, sometieron a los vasallos de sus señoríos a una inicua opresión cuyo fin último era engrosar las arcas señoriales» y sitúa a la tierra de Galisteo entre los escenarios más conflictivos. Para Medellín, Clemente Ramos, Julián, La tierra de Medellín (1234-c. 1450)..., págs. 174-181; Clemente Ramos, Julián, "Valdetorres, de dehesa a aldea (1409-1510). Poblamiento, conflicto y poder en la tierra de Medellín», Studia Historica. Historia Medieval, 20-21 (2002-3), págs. 54-62. Sobre los Estúñiga, cuyo dominio sobre Plasencia da lugar a un periodo especialmente conflictivo que afecta sobre todo a los señoríos de la tierra y a la oligarquía local, FRANCO SILVA, Alfonso y Del PINO García, José Luis, «El Campo de Arañuelo en el siglo XV: problemas y conflictos entre los señores de Oropesa y la ciudad de Plasencia», en: Estudios sobre ordenanzas municipales (siglos XIV-XVI), Cádiz, 1998, pág. 211; SÁNCHEZ LORO, Domingo, Historias placentinas inéditas, Cáceres, 3 vols., 1982-5, vol. II, pág. 410; LORA SERRANO, Gloria, "Conflictividad eclesiástica y conflictividad social en Plasencia y su tierra a fines de la Edad Media», Historia. Instituciones. Documentos, 31 (2004), págs. 383-386.

50 A. G. Simancas, Consejo Real, leg. 662, nº 2, fol. 29r. 
Los señores de Galisteo y futuros condes de Osorno van a adquirir igualmente importantes propiedades agrarias en Holguera. Desconocemos cuando comenzaron a realizar compras. En el último cuarto del siglo $\mathrm{XV}$, se sitúan entre los mayores propietarios. En el deslinde de las propiedades de Catalina Suárez realizado en 1479, sólo los herederos de Juan Sánchez de Garganta la Olla poseen un mayor número de parcelas ${ }^{51}$. En otros dos de la década siguiente, aparecen como primer y segundo propietario ${ }^{52}$. Un inventario de 1485 enumera las propiedades condales ${ }^{53}$. No sabemos si es exhaustivo o sólo se anotan las tierras de cereal. El conde de Osorno posee en este momento veintiséis parcelas, número bastante elevado si se compara con otros propietarios no vecinales (cf. Cuadro 1). Sin embargo, mientras los propietarios más antiguos han obtenido sus posesiones no mucho después del comienzo del proceso repoblador, el conde adquiere parcelas que en su totalidad o mayoritariamente pertenecen a propietarios locales. Seguramente, estamos ante parcelas de menor extensión. Los vendedores (Francisco de Heredia, Ruy González, Fernando de Sepúlveda, su madre y su mujer, o Inés Rodríguez) no han podido identificarse como miembros de ninguna oligarquía. Se trataría seguramente de campesinos.

El conde recibe a principios del siglo XVI, dentro de la hoja de cultivo, entre cuarenta y setenta fanegas. No queda claro si las recibe como propietario, y sus heredades se han integrado al igual que las de los vecinos en el nuevo terrazgo colectivo, o dentro del lote reservado a vecinos de Galisteo ${ }^{54}$. En todo caso, esta situación parece tener alguna vinculación con su condición de propietario local.

Se documentan dos compras importantes de Garcí Fernández Manrique en 1526. De este modo, el conde adquiere la herencia del comendador Hernando de Trejo consistente en ciento ochenta y tres fanegas de sembradura (catorce de ellas en Riolobos), el derecho a llevar quince yuntas de bueyes a la dehesa de Holguera $\mathrm{y}$ otros bienes de menor entidad ${ }^{55}$. Al menos la mitad de ellos fueron entregados en censo al concejo de Holguera, denotando un marcado interés rentista.

La entidad de los bienes adquiridos por los sucesivos condes de Osorno en Holguera queda clara con los censos que gravan a esta aldea a finales del siglo XVI, una vez finalizado el proceso de constitución de las hojas y de acensamiento de prácticamente toda la propiedad no vecinal. El conde recibe el 43,2\% del monto total. El siguiente propietario se sitúa en el 10,88\% (Cuadro 5). Esta proporción, de todos modos, es engañosa. El conde ha hecho valer su

51 A. Ch. Valladolid, Pleitos Civiles, Lapuerta (F), caja 1155, n ${ }^{\circ}$ 1, fols. 267r-270v.

52 A. Ch. Valladolid, Pleitos Civiles, Zarandona y Walls (Olv), caja 1851-1, no 2, fols. 141r149r y $252 \mathrm{r}-265 \mathrm{r}$.

53 A. Ch. Valladolid, Pleitos Civiles, Zarandona y Walls (Olv), caja 1851-1, nº 2, fols. 252r-265r.

54 A. G. Simancas, Consejo Real, leg. 662, nº 2, fols. 29v y 33r (AHN, Nobleza, Fernán Núñez, caja $\left.547, \mathrm{n}^{\circ} 1\right)$.

55 AHN, Nobleza, Fernán Núñez, caja 446/2, no 39; A. Ch. Valladolid, Pleitos Civiles, Zarandona y Walls (Olv), caja 1851-1, $\mathrm{n}^{\circ} 2$. En relación con las heredades no cerealistas, el conde acensó en 1534 la cuarta parte de un alcácer (AHN, Nobleza, Fernán Núñez, caja 547, nº 1). 
posición para obtener una mayor rentabilidad. Sin embargo, todo hace indicar que a mediados del siglo XVI sería el mayor propietario del término. Esto se ha debido, sin duda, a una clara política adquisitiva. Jurisdicción y propiedad dominical se dan la mano en la tierra de Galisteo. Holguera sólo parece ser un ejemplo bien documentado, pero seguramente no es el único en la margen izquierda del río Alagón ${ }^{56}$.

Los condes de Osorno, señores de la tierra de Galisteo, han desarrollado una clara política adquisitiva en el término de Holguera. A finales del XV aparecen entre los propietarios más importantes. Sus propiedades se componen posiblemente de un elevado número de parcelas medianas o pequeñas adquiridas a vecinos. Las compras realizadas en el siglo XVI, y en particular la adquisición de la herencia del comendador Hernando de Trejo, han debido convertir a la familia condal en la mayor propietaria del término. Su poder le garantiza su acensamiento en condiciones muy ventajosas.

\section{LA FORMACIÓN DE LAS HOJAS DE CULTIVO (C. 1485-C. 1550)}

El desarrollo de las hojas de cultivo supone un cambio profundo en la organización del terrazgo cerealista. El campesinado, acostumbrado hasta entonces a tomar decisiones de forma individual, se ve impelido a respetar una rotación colectiva preestablecida. Las hojas hacen además aconsejable una profunda reorganización agraria, entre cuyas posibilidades se encuentra la eliminación inicial de la propiedad privada, para posibilitar el cultivo de una extensión uniforme cada año.

Las hojas de cultivo responden a la necesidad de optimizar el aprovechamiento pecuario del espacio agrario ante la reducción de los espacios de pastos. Están unidas, por ello, a ocupaciones relativamente densas dentro de las formas específicas de ocupación y explotación del espacio ${ }^{57}$.

Las hojas de cultivo se documentan tardíamente en la corona de Castilla. En algunas zonas europeas, sin embargo, ya están constituidas en la plena

56 En Pozuelo de Zarzón, que presenta un terrazgo y una estructura productiva muy diferente, no se documentan propiedades condales (CLEMENTE RAMOS, Julián, «Propiedad, producción y paisaje...», págs. 252-4). Los condes de Osorno parecen acumular también propiedades en Riolobos o Valdeobispo (AHN, Nobleza, Fernán Núñez, caja 457, no 2).

57 Un procurador de Puebla de Don Rodrigo, en La Mancha, indica que las tierras se organizaron en hojas debido a la «mucha estrechura de términos y que, si cada uno sembrase donde su voluntad fuese, los ganados recibirían daño» (LÓPEZ-SALAZAR PÉREZ, Jerónimo, Estructura agraria y sociedad rural en La Mancha (ss. XVI-XVII), Ciudad Real, 1986, pág. 194; HuETZ DE LEMPS, Alain, «Les terroirs en Vieille Castille et Léon: un type de structure agraire», Annales.E.S.C., 17/2 (1962), pág. 248; RÖSENER, Werner, Los campesinos en la Edad Media, Barcelona, 1990, pág. 62; MilleR, Edward y HATCHER, John, Medieval England. Rural society and economic change, 1086-1348, Nueva York, 1985, págs. 95-6; MEYNIER, André, Les paysages agraires, París, 1959², pág. 158. 
Edad Media ${ }^{58}$. En la Península la existencia de una frontera en expansión entre los siglos XI y XIII ralentizó la colmatación demográfica de las zonas septentrionales y aún más de las meridionales. A finales del siglo XV, en una coyuntura de intenso crecimiento demográfico y agrario ${ }^{59}$, se empieza a constatar de modo bastante generalizado una escasez de bosques y pastos ${ }^{60}$.

Las hojas de cultivo constituyen una realidad en gestación a finales de la Edad Media y primera mitad del siglo XVI. Se documenta su existencia en la meseta. El comienzo del proceso debemos situarlo a finales del siglo XV y comienzos del XVI. A mediados de este siglo, han alcanzado cierta difusión ${ }^{61}$. En Extremadura al menos, ámbito que hemos abordado a escala regional, se han implantado en las zonas de importante dedicación cerealista ${ }^{62}$.

La coyuntura por la que atraviesa la tierra de Galisteo a finales del XV y principios XVI, en el momento en que empiezan a desarrollarse las hojas de cultivo en la margen izquierda del Alagón, se caracteriza como en el resto de la corona de Castilla por el crecimiento demográfico, la expansión del terrazgo agrario y la necesidad de regular más estrictamente los recursos silvícolas ${ }^{63}$. No parece que la jurisdicción de Galisteo ofrezca una escasez de bosques, pero sin duda los momentos de gran abundancia y tala indiscriminada o poco controlada pertenecen hacia 1500 al pasado.

58 DuBY Georges, Economía rural y vida campesina en el occidente medieval, Barcelona, 1973, pág. 218; THIRSK, Joan, «The common fields», Past E Present, 29 (1964), págs. 22-3; MiLler, Edward y HAtcher, John, Medieval England..., págs. 89-90; Fox, H.S.A., «Aproaches to the adoption of the Midland system», en: The origins of open-field agriculture, New Jersey, 1981, págs. 64-111; VERHULST, Adriaan, Le paysage rural: les structures parcellaires de l'Europa du Nord-Ouest, Turnhout, 1995, pág. 55; RÖSENER, Werner, Los campesinos en..., págs. 62-68.

59 En algunos casos se ha documentado con claridad como ha tocado techo el espacio cultivado: Oliva Herrer, Rafael Hipólito, La Tierra de Campos a fines de la Edad Media..., pág. 142; SÁnCHez Benito, José María, Las tierras de Cuenca y Huete..., pág. 536; RodríGUEZ LLOPIS, Miguel, Señoríos y feudalismo en el reino de Murcia. Los dominios de la Orden de Santiago entre 1440 y 1515, Murcia, 1984, págs. 212-3.

60 Casado Alonso, Hilario, Señores, mercaderes y campesinos..., págs. 37-8 y 235; ClemENTE RAMOS, Julián, «El medio natural en la vertiente meridional del Tajo extremeño en la Baja Edad Media», Anuario de Estudios Medievales, 30/1 (2000), págs. 326-331; Clemente Ramos, Julián, «Explotación del bosque y paisaje natural en la Tierra de Plasencia (1350-1550)», en: IX Congreso de Historia Agraria, Bilbao, 1999, págs. 443-6; MARTín CEA, Juan Carlos, El mundo rural castellano a fines de la Edad Media, págs. 124-5.

61 García FernándeZ, Jesús, "Champs ouverts et champs clôtures en Vieille-Castille», Annales.E.S.C, 20/4 (1965), págs. 702-3; SuÁreZ ÁlvareZ, Ma Jesús, La villa de Talavera y su tierra..., págs. 331-32; CASADO AlOnSO, Hilario, Señores, mercaderes y campesinos..., pág. 166.

62 Clemente Ramos, Julián: «La organización del terrazgo...», págs. 62-3.

63 Sobre el particular, Clemente RAmOS, Julián, «Desarrollo agrario y explotación forestal en la tierra de Galisteo a finales de la Edad Media», en: II Jornadas de Historia Medieval de Extremadura. Ponencias y comunicaciones, Mérida, 2005, págs. 61-66; sobre la problemática vinculada al bosque en Extremadura, Clemente RAMOS, Julián, «La evolución del medio natural en Extremadura (11421525)», en: El medio natural en la España medieval (Actas del I Congreso sobre ecobistoria e bistoria medieval), Cáceres, 2001, págs. 22-5. 
La situación de Holguera se ajusta a la de su entorno comarcal y jurisdiccional. El espacio agrario está colmatado y presenta escasas posibilidades de ampliación. Debemos considerar, además, el peso de la propiedad no vecinal y su coste económico. Se aprovechan algunos montes cercanos, seguramente próximos al río Alagón, fuera ya de su actual término municipal ${ }^{64}$. En el primer tercio del siglo XVI, se alcanza un pico demográfico. En 1531-2, Holguera contaba con noventa y ocho vecinos $\left(2,65\right.$ vecs. $\left./ \mathrm{km}^{2}\right)$, población que no se superará de forma nítida hasta principios del siglo $X^{65}$. A finales del $X V$ y principios del XVI, sus vecinos realizan cultivos en comunales de la tierra de Galisteo, aunque no sin problemas por no posicionarse junto a la villa y la mayor parte de las aldeas contra el conde de Osorno ${ }^{66}$. Disminución del bosque e intensa ocupación del termino aldeano son elementos de base que explican la reorganización profunda del terrazgo agrario que significan las hojas.

El desarrollo de las hojas de cultivo se realiza en Holguera en unas condiciones precisas definidas por la estructura de la propiedad y las relaciones con la autoridad jurisdiccional. Como hemos indicado, la propiedad no vecinal era posiblemente mayoritaria y, excluido el conde de Osorno, ajena en su totalidad a la tierra de Galisteo. Por ello, la formación de las hojas va a suponer una auténtica revolución en la propiedad agraria, al eliminarse la propiedad vecinal y controlarse de modo definitivo la no vecinal. De este modo, el acceso a la explotación de la tierra se va a facilitar y garantizar con unos censos en su conjunto módicos. Debemos considerar que este control de la mayor parte de la propiedad no vecinal debió contar con el beneplácito de la autoridad jurisdiccional porque, mediante el pago de unos censos limitados, se materializaba la desaparición de la escena de personas ajenas a la tierra de Galisteo y facilitaba un control más estricto del señorío. En el desarrollo de las hojas converge, por tanto, un doble interés vecinal y condal, lo que explica al menos en parte que Holguera participe de modo muy limitado en los pleitos contra el conde.

Las hojas de cultivo empiezan a formarse a finales del siglo XV. A mediados del siglo XVI, Alonso Martín Corchero señala que ha visto repartir las tierras de las diversas hojas «de mas de setenta años [c. 1485] a esta parte» ${ }^{67}$. No parece que esta afirmación sea inconsistente. A principios del siglo XVI, las hojas son una realidad perfectamente constituida.

64 «Riolobos e Holguera tyenen a Valtahajo e Cavanas Mojadas (¿Navasmojadas?) que es mas çercano donde podian cortar [madera]» (A. G. Simancas, Consejo Real, leg. 9, no 7/2, fol. 27r).

65 A. G. Simancas, Catastro de Ensenada, Respuestas Generales, lib. 142, f. 445v; Censo de 1787 «Floridablanca». Cáceres, Madrid, 1987, pág. 1168; MADOZ, Pascual, Diccionario históricogeográfico..., pág. 160; GARCÍA MARTíN, Bienvenido, El paisaje agrario de la tierra de Coria, sus transformaciones e incidencias, Cáceres-Salamanca, 1985, págs. 409, 414 y 418.

66 A. G. Simancas, Consejo Real, leg. 9, expág. 7, nº 1, fol. 1v.

67 A. Ch. Valladolid, Pleitos Civiles, Lapuerta (F), caja 1155, nº 1, fol. $145 \mathrm{v}$. 
CuAdro 4. CONCEJO DE HOLGUERA (1520-1547): ACENSAMIENTOS ENFITÉUTICOS

\begin{tabular}{|c|c|c|}
\hline año & heredades & censo \\
\hline c. 1520 & Heredades del monasterio de San Alfonso de Plasencia & $\begin{array}{l}\text { doce fanegas de trigo } \\
\text { y seis de cebada }\end{array}$ \\
\hline 1528 & $\begin{array}{l}\text { Heredades del bachiller Juan de Villalobos, vecino de Pla- } \\
\text { sencia (con anterioridad, el concejo de Holguera las había } \\
\text { tenido a censo «muchos años») }\end{array}$ & doce fanegas de trigo \\
\hline 1529 & Tres tierras de Juan del Bado, regidor del Barco de Ávila & 5,5 fanegas de trigo \\
\hline 1529 & $\begin{array}{l}\text { Tierras que pertenecen a Benito Martín, vecino de Gata, en } \\
\text { las Casas del Arroyo }\end{array}$ & siete fanegas de trigo \\
\hline 1529 & $\begin{array}{l}\text { Tierras que pertenecen a Francisco de Hontiveros, vecino } \\
\text { de Gata, en las Casas del Arroyo }\end{array}$ & $\begin{array}{l}\text { tres fanegas de trigo y } \\
\text { media de cebada }\end{array}$ \\
\hline 1531 & $\begin{array}{l}\text { Tierras que compro el conde de Osorno a Pedro de Rei- } \\
\text { noso, hijo de Juan de Reinoso, vecino de Carrión, que las } \\
\text { recibió de Pedro Manrique }\end{array}$ & $\begin{array}{l}\text { veinticinco fanegas de } \\
\text { trigo y quince de } \\
\text { cebada }\end{array}$ \\
\hline 1534 & $\begin{array}{l}\text { Tierras de los hermanos Diego Hernán de Retortillo, Alon- } \\
\text { so Calvo y María Díaz, cuyo marido es vecino de Cañaveral }\end{array}$ & $\begin{array}{l}\text { diez fanegas de trigo } \\
\text { y dos de cebada }\end{array}$ \\
\hline c. 1535 & $\begin{array}{l}\text { Heredades de Pedro Suárez y sus hermanos, vecinos de } \\
\text { Plasencia, consistente sobre todo en } 1 / 3 \text { de la antigua casa } \\
\text { y heredad del Acelgar }\end{array}$ & $\begin{array}{l}22,5 \text { fanegas de trigo } \\
\text { y diez de cebada }\end{array}$ \\
\hline 1536 & Tierras de Hernando de Trejo, vecino de Plasencia & $\begin{array}{l}\text { doce fanegas de trigo } \\
\text { y seis de cebada }\end{array}$ \\
\hline 1541 & $\begin{array}{l}\text { Haza del bachiller de Alonso Pérez Calvo y su mujer Isabel } \\
\text { Hernández, vecinos de Holguera }\end{array}$ & $\begin{array}{l}\text { catorce fanegas de } \\
\text { trigo y seis de cebada }\end{array}$ \\
\hline 1547 & $\begin{array}{l}\text { Tierras de Sevilla López de Carvajal (2/3), casada con el } \\
\text { regidor y vecino de Plasencia Gutierre González de Carva- } \\
\text { jal, e Isabel Suárez de Trejo (1/3), hermanas }\end{array}$ & $\begin{array}{l}\text { treinta fanegas de } \\
\text { trigo y tres fanegas de } \\
\text { cebada }\end{array}$ \\
\hline
\end{tabular}

\section{CuAdro 5. CONCEJO DE HOLGUERA (1594): CENSOS ENFITÉUTICOS}

\begin{tabular}{|c|c|c|c|}
\hline \multirow{2}{*}{ Propietario } & \multicolumn{2}{|c|}{ Censo (fans.) } & \multirow{2}{*}{$\begin{array}{l}\text { Fanegas de } \\
\text { sembradura }\end{array}$} \\
\hline & Trigo & Cebada & \\
\hline Conde de Osorno & 90 & 40,33 & - \\
\hline Catalina Mateos (vo Gata) & 7 & - & - \\
\hline Miguel Flores ( $\mathrm{v}^{\mathrm{o}}$ Plasencia) & 22,5 & 10 & - \\
\hline Monjas de San Alfonso de Plasencia & 12 & 6 & 350 \\
\hline Alonso Pérez de la Periana ( ${ }^{\circ}$ Cañaveral) & 12 & 6 & - \\
\hline Isabel Sánchez (va Aceúche) & 25 & 1 & - \\
\hline Doctor Pedro de Quirós (v ${ }^{\circ}$ Plasencia) & 12 & - & $136,5+2$ tierras \\
\hline Aldonza de Trejo, $\mathrm{v}^{\mathrm{a}}$ Plasencia & 20 & 2 & - \\
\hline Hospital de Holguera & 1,66 & 0,33 & - \\
\hline Iglesia de Holguera & 1 & - & - \\
\hline Juan Rodríguez (v $\mathrm{v}^{\mathrm{o}}$ Santa Cruz) & 23,83 & 9 & - \\
\hline Total & 226,99 & 74,66 & - \\
\hline
\end{tabular}


No han adquirido aún su forma definitiva, pero se han dado pasos decisivos. Sin duda, en un primer momento se han debido desarrollar a expensas fundamentalmente de la propiedad vecinal. El proceso ha debido ser voluntario, puesto que en 1541 un matrimonio de Holguera cede todas sus heredades al concejo mediante un censo enfitéutico. Una parte sensible de los vecinos ha renunciado a la propiedad de sus predios a cambio del derecho a recibir tierras en proporción a la disponibilidad de bueyes. En su gran mayoría serían medianos y pequeños campesinos. En el pleito que enfrenta al conde de Osorno y la tierra de Galisteo sobre el aprovechamiento del bosque se ofrecen algunas informaciones de gran interés ${ }^{68}$. A principios del siglo XVI las nuevas hojas debían contar con la casi totalidad o la mayor parte de la propiedad vecinal. Benito González, procurador de los vecinos de la tierra, acusa al conde de haber tomado ciento treinta fanegas para labrar «que fue de lo mejor», quizás fuera de hoja. El conde recibió en hoja entre setenta y cuarenta fanegas dentro de las "quarenta yuntas de la villa», de las que "ha de pagar terradgo porque es de heredero». No es seguro que las heredades del conde de Osorno hayan entrado en su totalidad en las nuevas hojas, aunque no se puede desestimar. Duarte Enrique, procurador del conde, indica, asimismo, que «a un vezino solo del dicho logar Olguera le copo çiento e veynte fanegadas de tierra en la dicha hoja». Las cuarenta yuntas de Galisteo debían labrar una parte minoritaria del terrazgo, pero en una rotación al tercio y dentro de las pautas que marcan las ordenanzas de Galisteo de 1531 requerían más de trescientas fanegas de cultivo y una disponibilidad de casi mil fanegas. Aunque no concedamos a estos datos una fiabilidad total, es evidente que las hojas integran hacia 1500 gran parte del terrazgo local.

Algunos herederos no vecinales han debido acensar total o parcialmente sus tierras desde fechas tempranas ${ }^{69}$. Las fanegas recibidas por el conde son como hemos visto tierra «terradguera», es decir, propiedad extravecinal sujeta a censos. El concejo acensó temporalmente algunas tierras antes de recibirlas mediante la modalidad enfitéutica ${ }^{70}$. Los acensamientos perpetuos sólo se documentan a partir de la tercera década del siglo XVI.

En esta fase se ha debido iniciar ya la eliminación del parcelario con la supresión de las lindes. Esto ha afectado a todo tipo de propiedades. Hay una

68 A. G. Simancas, Consejo Real, leg. 662, $\mathrm{n}^{\mathrm{0}} 2$, fols. 29v y 33r.

69 Es posible que en algún caso participen en alguna medida en las hojas. En 1526, García Fernández Manrique, conde de Osorno, compra la mitad de la herencia del comendador Hernando de Trejo a su hijo, incluyendo «el derecho que el dicho Françisco de Trejo tiene en el dicho lugar de Olguera de poder labrar con la mitad de quinze bueyes [la otra mitad correspondía a su hermana] en los terminos e baldios del dicho lugar de Olguera y con el derecho de pastar la dicha mitad de quinze bueyes en los terminos y baldios» (AHN, Nobleza, Fernán Núñez, caja 446/2, no 33, fol. 1r). Holguera, con un espacio intensamenteocupado, disponía en la primera mitad del siglo XVI de escasos baldíos, salvo que los «terminos e baldíos» aludan a las hojas de cultivo.

70 El bachiller Villalobos precisa en la entrega enfitéutica de sus propiedades en 1528 que «las abeis labrado [el concejo de Holguera] muchos años e me abeis pagado el terrazgo de ellas» (A. Ch. Valladolid, Pleitos Civiles, Lapuerta (Olv), caja 1226, nº 6, fol. 2v). 
noticia aislada, pero de extraordinario interés. Sebastián Gutiérrez, vecino de Plasencia, nos informa a mediados del siglo XVI de que hacia 1520 fue con Alonso de Carvajal, alcalde mayor de Galisteo, y Francisco Núñez de Almendras a ver ciertas tierras «terrazgueras» para «hazer çierto auto a los labradores vezinos del dicho lugar que aravan las dichas tierras» y vieron que se «ronpian las lindes», ordenando el bachiller Carvajal «que no ronpiesen las lindes» ${ }^{71}$. En la segunda década del siglo XVI, los vecinos de Holguera estaban eliminando el parcelario en un momento en que no controlaban aún gran parte de las tierras mediante censos permanentes. No parece que esto haya ocasionado grandes problemas. Sebastián Gutiérrez recuerda este detalle cuarenta años después de que sucediera porque tiene una relación indirecta con la pregunta realizada. Sin duda, el carácter mayoritariamente ajeno a la jurisdicción de los propietarios no vecinales debió dificultar cualquier respuesta en un proceso que parece contar con el apoyo del conde de Osorno.

El proceso de eliminación de los mojones de las parcelas debió ser largo. En las primeras décadas del siglo XVI se dieron o intentaron dar los primeros pasos. No faltan indicios. Cuando el bachiller Villalobos entregue sus propiedades mediante la modalidad enfitéutica, no se realizará ningún deslinde de las mismas sino que se incluyen sus límites por «escripturas ganadas de escribano publico». Del mismo modo, en otras ventas o acensamientos se enumeran las parcelas sin delimitarlas ${ }^{72}$. Sin embargo, el parcelario no ha desaparecido totalmente. En 1555, se realiza el apeo y deslinde de las propiedades de Francisco Suárez, heredero de su hermana Catalina, que formaron parte de la heredad del Acelgar ${ }^{73}$.

La completa organización de las hojas de cultivo se materializa con el sistemático acensamiento de toda la propiedad no vecinal del término (Cuadro 4). Este proceso se desarrolla entre 1520 y 1547. Algunas heredades, como hemos indicado, ya estaban acensadas temporalmente. De este modo se intenta la integración definitiva e irreversible de todo el terrazgo cerealista en las hojas. Los propietarios no ponen impedimentos. La percepción de una renta en especie impide su depreciación. Su nivel, sin embargo, es moderado. Según Pedro Suárez

«en este tiempo pressente [mediados del siglo XVI] muchas mas valen las dichas tierras de zenso e aun en el tiempo que se azenzuaron [1535] valian muchas mas segun la bondad de las dichas tierras e gran cantidad» ${ }^{74}$.

71 A. Ch. Valladolid, Pleitos Civiles, Lapuerta (F), caja 1155, $\mathrm{n}^{\circ} 1$, fol. $58 \mathrm{v}$.

72 A. Ch. Valladolid, Pleitos Civiles, Lapuerta (Olv), caja 1226, $\mathrm{n}^{\circ}$ 6, fol. 1v; A. Ch. Valladolid, Pleitos Civiles, Zarandona y Walls (Olv), caja 1851-1, no 2, fols. 178r y 181v; AHN, Nobleza, Fernán Núñez, caja 446/2, no 39.

73 A. Ch. Valladolid, Pleitos Civiles, Lapuerta (F), caja 1155, n ${ }^{\circ}$ 1, fols. 267r-270v.

74 A. Ch. Valladolid, Pleitos Civiles, Zarandona y Walls (Olv), caja 1851-1, no 2, fol. 297v. 
En dos casos podemos estimar el valor de la renta. Las monjas de San Alfonso de Plasencia acensan sus propiedades en Holguera en 1520 por doce fanegas de trigo y seis de cebada. No conocemos la totalidad de sus propiedades, pero en 1487 adquirieron doce parcelas que alcanzaban las trescientas treinta fanegas ${ }^{75}$. Considerando una rotación al tercio, una productividad de la simiente de cinco por uno y la utilización de una fanega de simiente por cada fanega de sembradura ${ }^{76}$, la renta sólo supondría como máximo un 3,27\% de la producción teórica bruta. En 1528, el bachiller Juan de Villalobos, vecino de Plasencia, acensa 138,5 fanegas de sembradura y dos tierras de una extensión no precisada por doce fanegas de trigo anuales ${ }^{77}$. En este caso, la renta alcanza el $5,20 \%$. Sin duda, estas obligaciones se sitúan en un nivel muy inferior al valor locativo de las heredades.

La familia condal cede sus bienes en condiciones mucho más favorables. A finales del siglo XVI, recibe el 43,20\% de las rentas enfitéuticas satisfechas por Holguera. En 1531, el conde García Manrique estableció sobre 91,5 fanegas de sembradura un censo de veinticinco fanegas de trigo y quince de cebada ${ }^{78}$. En este caso, la renta alcanza el $26,23 \%$ de la producción bruta teórica. Parece producirse un trasvase de renta que beneficia a la autoridad jurisdiccional frente al conjunto de los propietarios no vecinales. El concejo de Holguera se benefició, asimismo, de unas obligaciones enfitéuticas que no parece que superen en conjunto la décima parte de la producción bruta. El entendimiento entre esta aldea y la casa condal parece tener razones de peso.

A mediados del siglo XVI la constitución de las hojas es una realidad madura y así es percibida por los vecinos. En un interrogatorio presentado en 1555 por el concejo de Holguera dentro del pleito que mantiene con García Suárez de Carvajal, se señala que

«todas las tierras que ay y estan en termino del dicho lugar de Holguera son baldias e conçegiles e ningund vezino tiene ninguna tierra propia suya sino el conçejo las tiene todas repartidas en sus hojas»79.

75 A. Ch. Valladolid, Pleitos Civiles, Zarandona y Walls (Olv), caja 1851-1, no 2, fol. 145 r.

76 Un rendimiento de la semilla del 5 por 1 en las tierras cerealistas era normal en el siglo XVI en la corona de Castilla (VAssberg, David E., Tierra y sociedad en Castilla. Señores, poderosos y campesinos en la España del XVI, Barcelona, 1986, pág. 259; BRUMONT, Francis, Campos y campesinos de Castilla la Vieja en tiempos de Felipe II, Madrid, 1984, págs. 128-9; BenNaSAR, Bartolomé, Valladolid en el Siglo de Oro. Una ciudad de Castilla y su entorno agrario en el siglo XVI, Valladolid, 1983, pág. 240; Vela Santamaría, F. Javier y Marcos Martín, Alberto, «Las grandes ciudades campesinas de Andalucía occidental en el siglo XVI. El caso de Jerez de la Frontera», en: Actas del I Congreso de Historia de Andalucía. Andalucía moderna (siglos XVI-XVII), Córdoba, 1978, vol. II, págs. 403-417).

77 A. Ch. Valladolid, Pleitos Civiles, Lapuerta (Olv), caja 1226, n 6, fols. 1r-3v.

78 AHN, Nobleza, Fernán Núñez, caja 446/2, nº 39.

79 SÁnCHez Gómez, Luis Ángel, Sayago, ganadería..., pág. 42 indica frente al presunto arcaísmo de ciertas prácticas comunales como «solo a partir del siglo XVIII constatamos en casi 


\section{Juan Pérez de Perogómez precisa que}

«nunca bio que ubiese ynpedimiento de tierras ni suertes acensuadas para que ynpediese la partija sino todo se partia e repartia como caya en la hoja como baldio conçejil y como tal lo beya labrar a los vezinos deste lugar» 80 .

De forma más o menos implícita, esta misma postura mantienen prácticamente todos los testigos presentados. Aunque quizás no se hubiera eliminado completamente el parcelario, la propiedad vecinal ha desaparecido y la no vecinal se ha integrado completamente en las hojas. El carácter perpetuo de los acensamientos tomados por el concejo de Holguera dota de total estabilidad a este proceso.

Desde el primer momento se forman tres hojas. En un pleito con Riolobos de finales del siglo XVI, se alude a «las tres oxas del lugar de Olguera que son Valdelabaca, y el prado del Hito y la Vega (...) y tanbien la hoxa de la Torrezilla y Peñaja». La sentencia del alcalde mayor de Galisteo de 1596 solo menciona «Valdelabaça y el prado del Hito y la Vega y hoja de la Torreçilla». En 1598 se alude a «tres ojas que se dividen en tres terçios que llaman Baldelabaca y la Torreçilla y el prado el Hito» ${ }^{81}$. Todo nos hace pensar que las hojas serían Valdelavaca, Prado del Hito-Vega y Torrecilla-Peñaja. Sin duda, son las mismas que se han mantenido, quizás con alguna pequeña variación, hasta después de la Guerra Civil.

La creación de tres hojas va unida a una rotación al tercio ${ }^{82}$. En el pleito que mantienen Holguera y García Suárez de Carvajal a mediados del siglo XVI, los diversos testigos avalan repetidamente este detalle ${ }^{83}$. Cada año se cultiva una hoja. El cultivo al tercio permitiría un importante aprovechamiento

todos los pueblos sayagueses la existencia de labrantío comunal repartido anualmente». Creemos que ahora puede contextualizarse adecuadamente el origen de estas prácticas que afectan al terrazgo permanente cerealista y vincularse a la reorganización que implican la formación de las hojas de cultivo.

80 A. Ch. Valladolid, Pleitos Civiles, Lapuerta (F), caja 1155 , no 1 , fols. 119v y 121v.

81 A. Ch. Valladolid, Pleitos Civiles, Zarandona y Walls (Olv), caja 1851-1, $\mathrm{n}^{\circ}$ 2, fol. 32v y 441r; A. Ch. Valladolid, Pleitos Civiles, Zarandona y Walls (Olv), caja 1754, $\mathrm{n}^{\circ}$ 1, fol. $35 \mathrm{r}$.

82 Resulta llamativo que estemos siempre ante tres o más hojas, algo que habría que vincular a los cambios que desde la baja Edad Media se producen en las rotaciones cerealistas y, en particular, al receso de la bienal o de año y vez al sur del Sistema Central (Clemente Ramos, Julián, «La organización del terrazgo...», pág. 62; CLEMENTE RAMOS, Julián, «Agrosistemas hispanocristianos: el secano (Corona de Castilla, siglos X-XV)», en: Cristiandad e Islam en la Edad Media hispana (XVIII Semana de Estudios Medievales), Logroño, 2008, págs. 268-9; BERNAl EstÉveZ, Ángel, El concejo de Ciudad Rodrigo y su tierra durante el siglo XV, Salamanca, 1989, pág. 370; LÓPEZ-SALAZAR PÉREZ, Jerónimo, Estructura agraria y sociedad rural..., pág. 194; VASSBERG, David E., Tierra y sociedad en Castilla..., pág. 73).

83 A. Ch. Valladolid, Pleitos Civiles, Lapuerta (F), caja 1155, $\mathrm{n}^{\circ}$ 1, fols. 123r-145v (probanza de Holguera; pregunta 2). 
pecuario ${ }^{84}$. Será este aprovechamiento el que origine en la segunda mitad del siglo XVI el enfrentamiento con Riolobos ${ }^{85}$. Mientras Riolobos defiende su derecho a explotar los rastrojos y los espacios incultos de la tierra de Galisteo, Holguera intenta imponer un aprovechamiento local exclusivo fundamentándose en los terrazgos que paga, vinculados exclusivamente al cultivo de la tierra.

El cultivo de las hojas se corresponde en su totalidad con las normativas de las ordenanzas de Galisteo ${ }^{86}$. El concejo de Holguera establece con gran claridad el procedimiento de reparto anual de las heredades:

«todas las tierras que ay y estan en termino del dicho lugar de Holguera son baldias e conçegiles, e ningund vezino tiene ninguna tierra propia suya sino el conçejo las tiene todas repartidas en sus hojas, y cada un año reparten la una hoja y dan tierras a todos los vezinos del dicho lugar segund tienen las yuntas para poder labrar, y el que sienbra una tierra en una sazon e año no la sienbra otra bez sino aquel que le cabe por suerte y ansi ninguno tiene propiedad ni es señor de ningun pedaço de tierra para poder cargar sobre el algun censo» 87 .

Los pobres que no disponen de yuntas reciben «sus senaras», de las que desconocemos sus características ${ }^{88}$. La roturación de un terreno no da derecho a su propiedad, sino a un simple usufructo. El padre de Lucas Durán «desquajo e linpio parte de las suertes que les cabia en el dicho valdio y alçado el fruto quedabase pasto comun». Como indica Pedro Martín Santiago sobre las tierras cultivadas «el que lo labra y desquaja y linpia lo haze por aprobecharse aquel año della y alçado el fruto queda baldio y concejil» ${ }^{89}$.

No se alude de modo directo a la cantidad entregada por yunta, algo sin duda variable. Las ordenanzas de Galisteo marcan una extensión de ocho a diez fanegas en la margen izquierda del río Alagón ${ }^{90}$. Es llamativo que el comendador Hernando de Trejo en el momento de su muerte, acaecida poco antes de 1526, tuviese derecho a cultivar con quince bueyes en los términos y baldíos de Holguera. Si esto mantiene relación con sus propiedades (ciento sesenta y nueve fanegas de sembradura), en una rotación al tercio a cada yunta le corresponderían 7,51 fanegas y en un sistema de año y vez 11,27 fanegas, extensiones no muy alejadas de las establecidas en las ordenanzas ${ }^{11}$.

84 García Fernández, Jesús, «Los sistemas de cultivo de Castilla la Vieja», en: Aportación española al XX Congreso Geográfico Internacional, Madrid-Zaragoza-Barcelona, 1964, págs. 144-5; SUMPSI, José $\mathrm{M}^{\mathrm{a}}$, «Estudio de la transformación del cultivo al tercio al de año y vez en la Campiña de Andalucía», Agricultura y sociedad, 6 (1978), págs. 33-34

85 A. Ch. Valladolid, Pleitos Civiles, Zarandona y Walls (Olv), caja 1851-1, no 2.

86 Clemente Ramos, Julián, Ordenanzas de Galisteo..., págs. 33-4.

87 A. Ch. Valladolid, Pleitos Civiles, Lapuerta (F), caja 1155, no 1, fol. 119v.

88 A. Ch. Valladolid, Pleitos Civiles, Lapuerta (F), caja 1155, no 1, fol. $145 \mathrm{v}$.

89 A. Ch. Valladolid, Pleitos Civiles, Lapuerta (F), caja 1155, no 1 , fols. 119v y 128v.

90 Clemente Ramos, Julián, Ordenanzas de Galisteo..., págs. 30 y 77.

91 AHN, Nobleza, Fernán Núñez, caja 446/2, nº 33, fol. 1r. 
En un principio, no sólo la comunidad local participa en el cultivo de las hojas de Holguera. Sin duda, esto hay que vincularlo con los derechos generales de los habitantes de la jurisdicción sobre todo el término. En particular, algunos o bastantes vecinos de Galisteo también reciben inicialmente tierras en el reparto ${ }^{92}$. En la segunda mitad del siglo XVI todo hace pensar que sólo reciben tierras los vecinos de Holguera. Testigos interrogados en diversos pleitos no aluden a otra posibilidad. La participación en el reparto se deriva siempre de la residencia en esta localidad ${ }^{93}$.

Una vez cosechado el cereal, las tierras se abren al aprovechamiento colectivo. El concejo de Holguera ha intentado reservarse en algún momento del siglo XVI su aprovechamiento exclusivo. En la tierra de Galisteo, por el contrario, los rastrojos independientemente de su ubicación pueden ser aprovechados por cualquier vecino de la jurisdicción. En todo caso, este derecho general no ha debido impedir que cada aldea o la propia villa aprovechen los suyos de modo preferente o casi exclusivo. En el caso de Holguera, el intento de impedir el acceso a otros vecinos ha generado la oposición de Riolobos. Se plantea en este caso el enfrentamiento con una aldea de mayor peso demográfico y más fuerte sociabilidad. Holguera sigue, en este campo, una estrategia defensiva que parece contar con el apoyo de las autoridades de la jurisdicción. No verá finalmente reconocida sus pretensiones que chocan con unas costumbres agrarias asentadas ${ }^{94}$.

\section{CONCLUSIONES}

Holguera presenta una evolución nítida entre la ocupación cristiana, ya iniciada en 1220, y mediados del siglo XVI, aunque una escasa documentación nos impide precisar con detalle sus ritmos cronológicos. Ubicada en el valle medio del Alagón, en un territorio alomado de buenos suelos, debió desarrollar muy pronto una importante dedicación cerealista. El proceso de ocupación contó con una participación no vecinal importante. En un primer momento, la oligarquía de Galisteo debió jugar un papel relevante aunque poco documentado, pero desde finales del siglo XIV ha sido sustituida sobre todo por vecinos e instituciones religiosas de Plasencia. A principios del siglo $\mathrm{XV}$, el terrazgo agrario, incluyendo por su funcionalidad la dehesa boyal y el ejido, ha alcanza-

92 A. G. Simancas, Consejo Real, leg. 662, n 2, fol. 29v.

93 En el pleito entre el concejo de Holguera y García Suárez de Carvajal aparecen algunos vecinos de Riolobos que recibieron tierra en las hojas mientras residían en esta localidad (A. Ch. Valladolid, Pleitos Civiles, Lapuerta (F), caja $1155, \mathrm{n}^{\circ} 1$, fols. 203 r y ss.).

94 A. Ch. Valladolid, Pleitos Civiles, Zarandona y Walls (Olv), caja 1851-1, $\mathrm{n}^{\circ}$ 2, fols. 440v441r (sentencia del Alcalde Mayor de Galisteo favorable a Holguera, a. 1596); A. Ch. Valladolid, Pleitos Civiles, Zarandona y Walls (Olv), caja 1754, $\mathrm{n}^{\circ} 1$, fol. 35 (sentencia definitiva favorable a Riolobos, a. 1598). 
do a grandes rasgos los límites actuales. Esto imposibilita cualquier crecimiento significativo del espacio cultivado dentro del estricto término local. El abastecimiento de productos silvícolas, que se enfrenta a crecientes dificultades y limitaciones, se realiza en espacios relativamente próximos de la jurisdicción.

MAPA 1. El ESPACIO AGRARIO DE HOlgUeRA (SIGLOS XIII-XVI)

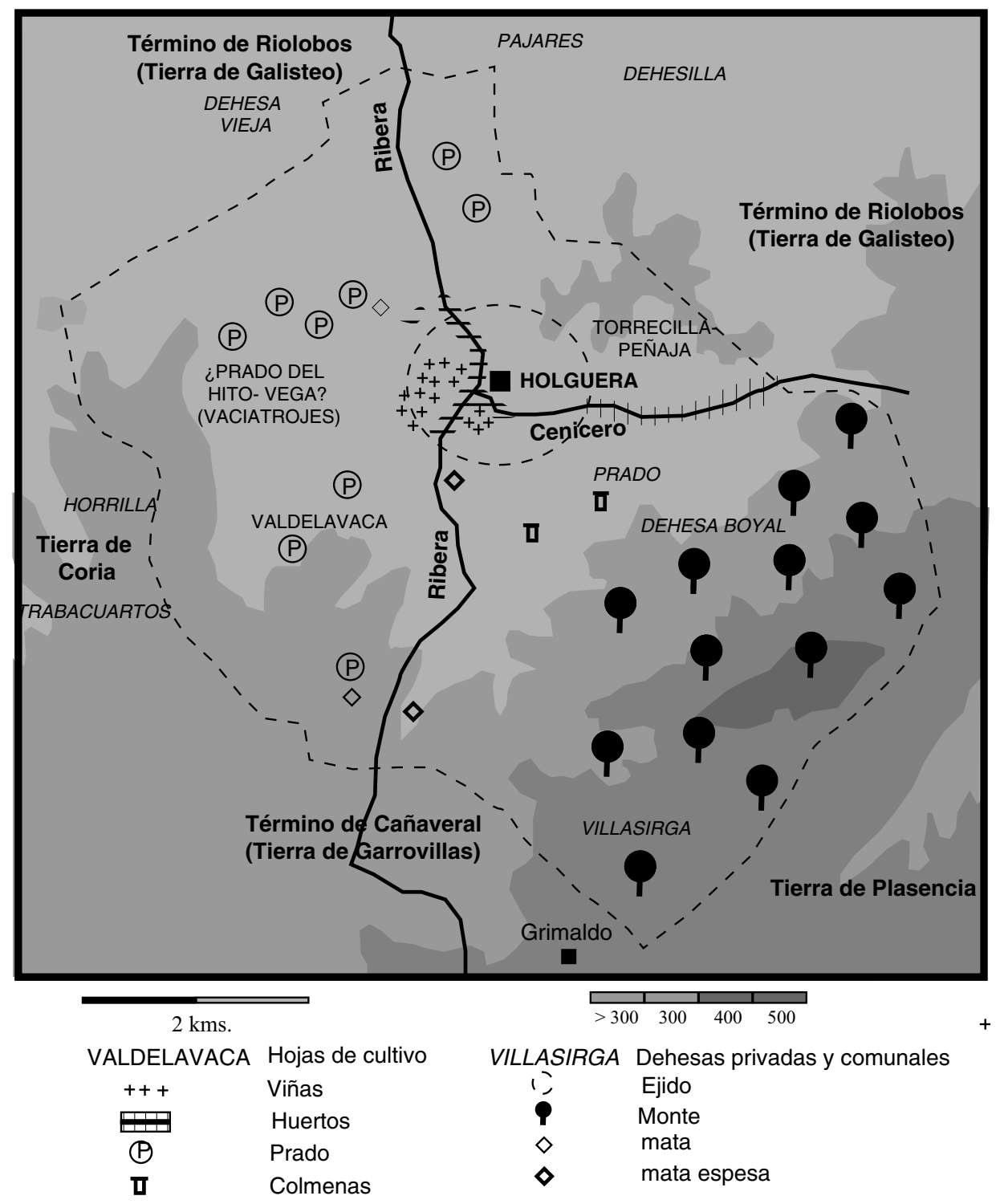


Esta situación ha marcado la evolución de las estructuras agrarias. En la primera mitad del siglo XVI se desarrolla una nueva organización del terrazgo agrario que va a permitir una mayor integración agroganadera. Se han formado tres hojas de cultivo en las que se practica una rotación al tercio. Se ha eliminado la propiedad vecinal y se ha absorbido la no vecinal mediante censos enfitéuticos, relativamente livianos salvo los condales, que obligan en conjunto al pago anual de trescientas fanegas de cereal. A mediados del siglo XVI, el control de todo el terrazgo local por el concejo de Holguera es un hecho. Esto ha abierto el camino a la eliminación del parcelario, algo no consumado pero, con seguridad, muy avanzado hacia 1550 . Este proceso de cambio ha contado con el beneplácito de la autoridad jurisdiccional.

A mediados del siglo XVI, se ha impuesto al igual que en otras muchas localidades extremeñas un terrazgo colectivo organizado en hojas. Las tierras se reparten anualmente en función de los bueyes poseídos. Este proceso está vinculado al contexto económico y demográfico. El crecimiento de la población y la intensa ocupación del espacio son factores que han propiciado la reorganización del espacio cerealista con el fin de optimizar su aprovechamiento pecuario.

Recibido: 12-02-2008

Aceptado: 03-07-2008 